\title{
Coordination Networks Based on Boronate and Benzoxaborolate Ligands
}

\author{
Saad Sene ${ }^{1}$, Marie Alix Pizzoccaro ${ }^{1}$, Joris Vezzani ${ }^{1}$, Marc Reinholdt ${ }^{1}$, Philippe Gaveau ${ }^{1}$, \\ Dorothée Berthomieu ${ }^{1}$, Sylvie Bégu ${ }^{1}$, Christel Gervais ${ }^{2}$, Christian Bonhomme ${ }^{2}$, \\ Guillaume Renaudin ${ }^{3,4}$, Adel Mesbah ${ }^{5}$, Arie van der Lee ${ }^{6}$, Mark E. Smith ${ }^{7,8}$ and \\ Danielle Laurencin ${ }^{1, *}$ \\ 1 Institut Charles Gerhardt de Montpellier, UMR 5253, CNRS UM ENSCM, Montpellier 34095, France; \\ senesaad@gmail.com (S.S.); pizzo.m-alix@live.fr (M.A.P.); jorisvezzani@gmail.com (J.V.); \\ marc.reinholdt@univ-poitiers.fr (M.R.); philippe.gaveau@univ-montp2.fr (P.G.); \\ dorothee.berthomieu@enscm.fr (D.B.); sylvie.begu@enscm.fr (S.B.) \\ 2 Laboratoire de Chimie de la Matière Condensée de Paris, UMR 7574, Sorbonne Universités, \\ UPMC Univ Paris 06, CNRS, Collège de France, Paris 75252, France; christel.gervais_stary@upmc.fr (C.G.); \\ christian.bonhomme@upmc.fr (C.B.) \\ 3 Université Clermont Auvergne, SIGMA Clermont, Institut de Chimie de Clermont-Ferrand, BP 10448, \\ F-63000 Clermont-Ferrand, France; guillaume.renaudin@sigma-clermont.fr \\ 4 CNRS, UMR 6296, ICCF, F-63178 Aubière, France \\ 5 Institut de Chimie Séparative de Marcoule, UMR 5257, CNRS CEA UM ENSCM, Bagnols-sur-Cèze 30207, \\ France; adel.mesbah@gmail.com \\ 6 Institut Européen des Membranes, CNRS-UMR 5635, UM, Montpellier 34095, France; \\ avderlee@univ-montp2.fr \\ 7 Vice-Chancellor's Office, University House, Lancaster University, Lancaster LA1 4YW, UK; \\ m.e.smith@lancaster.ac.uk \\ 8 Magnetic Resonance Centre, Department of Physics, University of Warwick, Coventry CV4 7HS, UK \\ * Correspondence: danielle.laurencin@umontpellier.fr; Tel.: +33-4-6714-3802
}

Academic Editors: Umit B. Demirci, Philippe Miele and Pascal G. Yot

Received: 29 March 2016; Accepted: 27 April 2016; Published: 2 May 2016

\begin{abstract}
Despite the extensive range of investigations on boronic acids $\left(\mathrm{R}-\mathrm{B}(\mathrm{OH})_{2}\right)$, some aspects of their reactivity still need to be explored. This is the case for the coordination chemistry of boronate anions $\left(\mathrm{R}-\mathrm{B}(\mathrm{OH})_{3}{ }^{-}\right.$), which has only recently been started to be studied. The purpose of this review is to summarize some of the key features of boronate ligands (and of their cyclic derivatives, benzoxaborolates) in materials: (i) coordination properties; (ii) spectroscopic signatures; and (iii) emerging applications.
\end{abstract}

Keywords: boronate; tri-hydroxyborate; benzoxaborolate; boronic acid; benzoxaborole; coordination polymer; solid state NMR; IR spectroscopy; crystallography; DFT

\section{Introduction}

Boronic acids $\left(\mathrm{R}-\mathrm{B}(\mathrm{OH})_{2}\right)$ are a family of molecules which present a wide range of applications [1]. Their main use is as reagents in the Miyaura-Suzuki coupling reaction (2010 Nobel Prize), for the formation of C-C bonds. Their reactivity is also of great interest for other fields [2-6], like in organocatalysis [2] and for the development of sensors (detection of carbohydrates, $\mathrm{H}_{2} \mathrm{O}_{2}$, fluoride anions, etc.) [3]. It has also been shown that some boronic acids can play the role of enzyme inhibitors [6], as is the case for bortezomib (Velcade ${ }^{\circledR}$ ), an anticancer molecule used for the treatment of multiple myeloma (Figure 1).

Benzoxaboroles are cyclic derivatives of boronic acids [7]. While the first synthesis of a benzoxaborole dates back to 1957, it is only in 2006 that the research community regained interest in 
these molecules, due to their capacity to bind to sugars at physiological $\mathrm{pH}$, moreover with a higher affinity than the corresponding boronic acids [8]. This property has since been widely exploited, notably in the biomedical field, where a variety of benzoxaborole-based drugs have been developed, with antifungal, anti-inflammatory, antimicrobial, antiprotozoal, antiviral or anticancer properties. In 2014, the first benzoxaborole-based drug, tavaborole (AN2690-Figure 1), received FDA approval for the treatment of onychomycosis [9].

bortezomib<smiles>CC(C)C[C@H](NC(=O)[C@H](Cc1ccccc1)NC(=O)c1cnccn1)B(O)O</smiles>

tavaborole (AN2690)<smiles>OB1OCc2cc(F)ccc21</smiles>

Figure 1. Representation of the structures of two organoboron drugs commercialized for their anti-cancer (left) and antifungal (right) properties.

In addition to applications in molecular chemistry, boronic acids and benzoxaboroles are also increasingly used in materials chemistry $[1,7,10,11]$. In most cases, the organoboron function is exposed at the periphery of the material so that its intrinsic reactivity can be exploited to provide a given property to the material (e.g., capacity to bind to diols). This is for example the case for polymers developed for the detection of dopamine [12], for chromatographic columns designed for the separation of sugars [11,13], and for mesoporous silica nanoparticles allowing the controlled release of insulin [14]. Another possibility which has been looked into consists of using the boronic acids themselves as building blocks for the preparation of functional (nano)materials. For example, covalent organic frameworks (COFs) have been synthesized from boronic acid precursors, in view of gas storage and molecular electronics applications [10,15].

In contrast to boronic acids and benzoxaboroles, their anionic counterparts, boronates and benzoxaborolates, had up until recently hardly been looked into as possible building blocks for materials applications. This is surprising considering the large number of studies involving other organic oxo-anions like phosphonates $\left(\mathrm{R}-\mathrm{PO}_{2}(\mathrm{OH})^{-}, \mathrm{R}_{-} \mathrm{PO}_{3}{ }^{2-}\right)$ and carboxylates $\left(\mathrm{R}-\mathrm{COO}^{-}\right)$which can be found in the literature, where they serve as building blocks for the preparation of coordination networks or Metal Organic Frameworks (MOFs), and more generally hybrid organic-inorganic materials. The purpose of this article is thus to highlight the work performed over the past five years regarding the preparation of the first materials based on boronate and benzoxaborolate units, in which the boron is in a tetrahedral configuration (Figure 2).

In the first part, the intrinsic coordination properties of boronate and benzoxaborolate anions will be described, by looking at the crystal structures of phases prepared starting from very simple boronic acids and benzoxaboroles. In the second part, the spectroscopic signatures of boronates and benzoxaborolates in these materials will be highlighted, as they are of importance for the study of more complex hybrid organic-inorganic materials, for which, in some cases, no crystal structure is available. Finally, in the third part, the importance of boronates/benzoxaborolates for the preparation of new families of materials will be underscored, and emerging applications of (nano)materials involving these anions will be highlighted. 
<smiles>[R]B(O)O</smiles>

boronate<smiles>[R][Se](O)(O)O</smiles>

(a) benzoxaborole<smiles>OB1OCc2ccccc21</smiles>

benzoxaborolate<smiles></smiles>

(b)

Figure 2. Representation of the structures of boronic acids/boronates (a); and benzoxaboroles/ benzoxaborolates $(\mathbf{b})$. Only the tetrahedral-boron forms of boronate/benzoxaborolate anions are shown here.

\section{Crystal Structures Involving Simple Boronates and Benzoxaborolates}

\subsection{Acid-Base Properties of Boronic Acids and Benzoxaboroles}

In water, boronic acids and benzoxaboroles behave as Lewis acids. Their conjugate bases are the boronate (also called tri-hydroxyborate) and benzoxaborolate anions, in which the boron is in a tetrahedral environment (Figure 2). The tetrahedral nature of the boronate anion was elucidated in 1959 [16], but it is only in 2006 that a crystal structure involving such a boronate anion was described for the first time [17].

The $\mathrm{p} K_{\mathrm{a}}$ of the boronic acid/boronate couple is generally $>8$, and depends on the nature of the organic chain linked to the boron [1]. For phenylboronic acid $\left(\mathrm{C}_{6} \mathrm{H}_{5}-\mathrm{B}(\mathrm{OH})_{2}\right)$, the $\mathrm{p} K_{\mathrm{a}}$ is $\sim 8.9$ (and thus similar to that of boric acid $\left.\mathrm{B}(\mathrm{OH})_{3}\right)$, while for methylboronic acid it is $\sim 10.4[1,18]$. The $\mathrm{p} K_{\mathrm{a}}$ of the benzoxaborole/benzoxaborolate couple is $\sim 7.3$ due to the cyclic form of the organoboron function. For benzoxaboroles, $\mathrm{p} K_{\mathrm{a}}$ values vary depending on the nature of the substituents on the aromatic ring, as well as on the methylene group [19]. It is worth noting that the $\mathrm{p} K_{\mathrm{a}}$ values of boronic acids and their derivatives are globally higher compared to those of other organic acids such as carboxylic and phosphonic (Table 1).

Table 1. $\mathrm{p} K_{\mathrm{a}}$ values (in water, at $25^{\circ} \mathrm{C}$ ) of simple boronic acids/benzoxaboroles, in comparison to other organic acids.

\begin{tabular}{ccc}
\hline Acid-Base Couple & $\mathbf{p K} \boldsymbol{K}_{\mathbf{a}}$ & Reference \\
\hline $\mathrm{C}_{6} \mathrm{H}_{5}-\mathrm{B}(\mathrm{OH})_{2} / \mathrm{C}_{6} \mathrm{H}_{5}-\mathrm{B}(\mathrm{OH})_{3}{ }^{-}$ & $\sim 8.9$ & {$[1]$} \\
$\mathrm{CH}_{3}-\mathrm{B}(\mathrm{OH})_{2} / \mathrm{CH}_{3}-\mathrm{B}(\mathrm{OH})_{3}{ }^{-}$ & 10.4 & {$[18]$} \\
$\mathrm{C}_{7} \mathrm{H}_{6} \mathrm{BO}(\mathrm{OH}) / \mathrm{C}_{7} \mathrm{H}_{6} \mathrm{BO}(\mathrm{OH})_{2}{ }^{-1}$ & $\sim 7.3$ & {$[19]$} \\
$\mathrm{CH}_{3} \mathrm{COOH} / \mathrm{CH}_{3} \mathrm{COO}^{-}$ & 4.8 & {$[20]$} \\
$\mathrm{CH}_{3}-\mathrm{PO}(\mathrm{OH})_{2} / \mathrm{CH}_{3}-\mathrm{PO}_{2}(\mathrm{OH})^{-}$ & 2.2 & {$[21]$} \\
$\mathrm{CH}_{3}-\mathrm{PO}_{2}(\mathrm{OH})^{-} / \mathrm{CH}_{3}-\mathrm{PO}_{3}{ }^{2-}$ & 7.5 & {$[21]$} \\
\hline
\end{tabular}

In boronates and benzoxaborolates, the negative charge is shared between the three oxygen atoms. This is what makes these anions attractive for coordination chemistry applications, as they can potentially play the role of tridentate ligands with respect to metal cations. Examples along this line are provided in the following sub-sections. 


\subsection{Boronate-Based Crystal Structures with Alkaline-Earth Metals}

A series of investigations aiming at describing the intrinsic coordination properties of the $\mathrm{R}-\mathrm{B}(\mathrm{OH})_{3}{ }^{-}$anions in materials have been reported [22-24]. Boronic acids bearing non-coordinating $\mathrm{R}$ - chains were used for this purpose $\left(\mathrm{R}-=\mathrm{C}_{6} \mathrm{H}_{5^{-}}, \mathrm{C}_{4} \mathrm{H}_{9^{-}}, \mathrm{C}_{8} \mathrm{H}_{17^{-}}\right)$, in order to ensure that the materials would form only based on the metal-ligand interactions. Reactions were carried out in water (or in water-ethanol mixtures), by adding a solution of a metal cation into a solution of the boronate (Figure 3), in order to precipitate a crystalline phase (e.g., a coordination polymer). Due to the high $\mathrm{p} K_{\mathrm{a}}$ values of the boronic acid/boronate couples, alkaline-earth metal cations were selected for the precipitation. Indeed, these ions should not lead to the competitive formation of metal-hydroxide precipitates during the reaction, in contrast with most other metal ions [20].
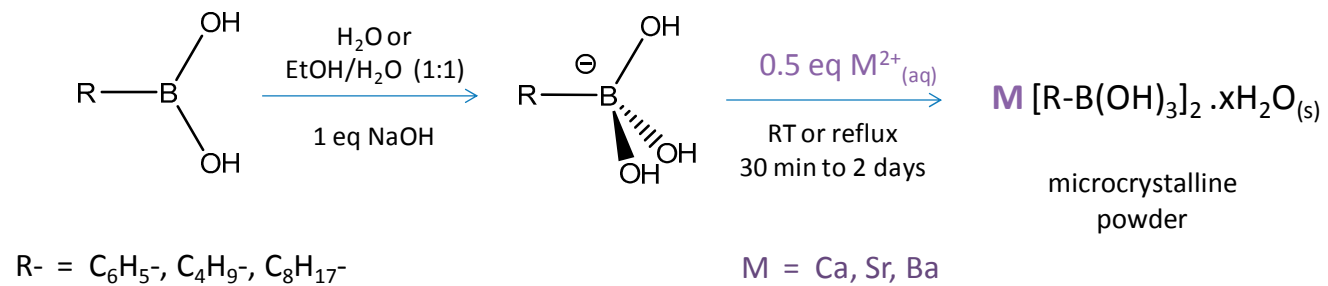

Figure 3. Reaction scheme for the formation of metal boronate crystalline structures by precipitation.

Materials were isolated in most cases as microcrystalline powders [22-24]. Scanning electron microscopy (SEM) analyses showed that in many cases, the crystallites had a sheet-like morphology, as illustrated in Figure 4 for the Sr-phenylboronate monohydrate and Sr-butylboronate phases. Structure determination was made possible by $(i)$ recording $X$-ray diffraction powder patterns using synchrotron radiation; (ii) performing a series of additional characterization (notably by IR and solid state NMR); (iii) modeling the structures computationally, notably to position the hydrogen atoms and to compute the NMR parameters. All materials were found to present a layered arrangement. More specifically, they were found to be made of planes of metal cations interconnected by boronate ligands, with the organic chains facing each other in the interlayer space (Figure 4).
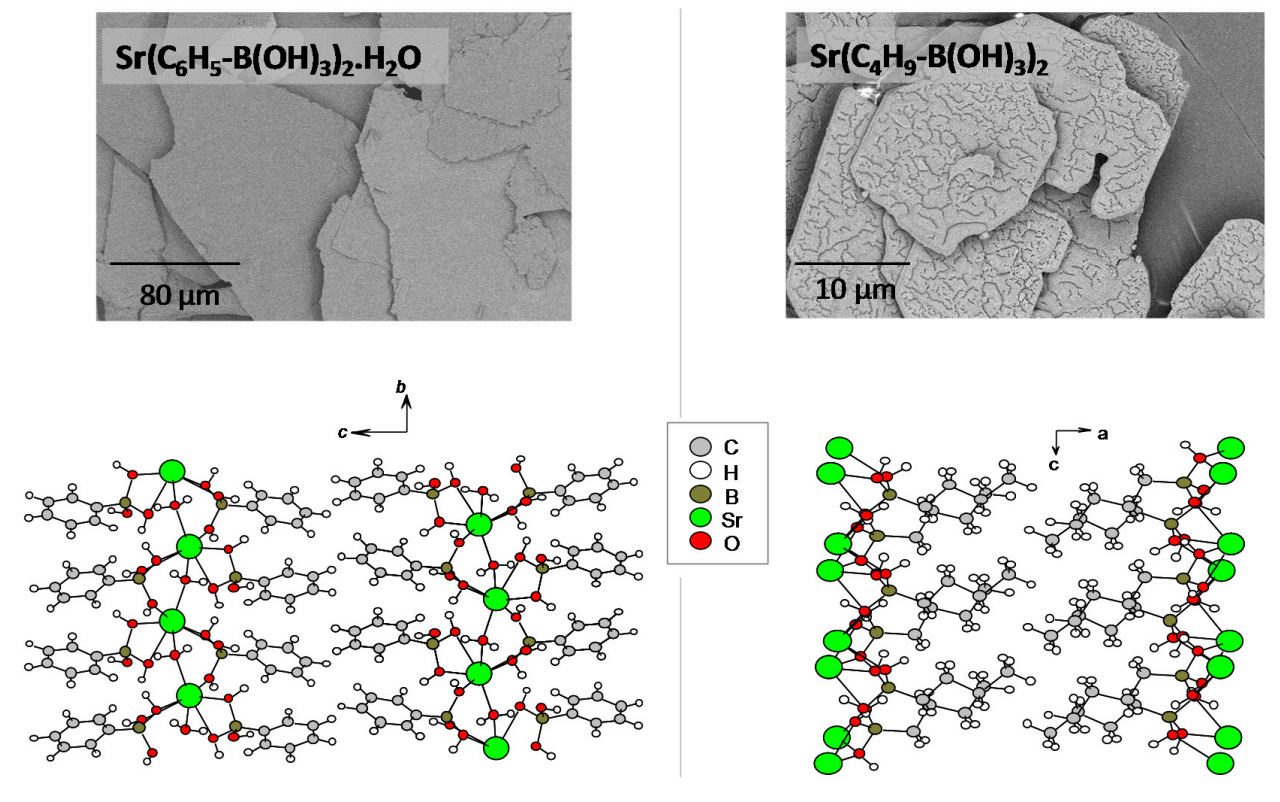

Figure 4. SEM images and crystal structures of $\mathrm{Sr}\left(\mathrm{C}_{6} \mathrm{H}_{5}-\mathrm{B}(\mathrm{OH})_{3}\right)_{2} \cdot \mathrm{H}_{2} \mathrm{O}(\mathbf{l e f t})$ and $\mathrm{Sr}_{2}\left(\mathrm{C}_{4} \mathrm{H}_{9}-\mathrm{B}(\mathrm{OH})_{3}\right)_{2}$ (right). Adapted with permission from [22] (copyright American Chemical Society, 2011), [24] (copyright Wiley-VCH Verlag 2013) and [25] (copyright Actualité Chimique, 2014). 
Based on the different crystal structures solved, the coordination modes of the boronates could be determined. These anions were found to play the role of bridging ligands, by coordination to two to three distinct alkaline-earth metals (Figure 5). This demonstrates that boronates, in which the boron atom is in a tetrahedral geometry, can serve as building blocks for the construction of coordination networks. Another possibility, not developed in this review but which further underscores the versatility of boronate ligands, concerns the use of the deprotonated boronate forms (in which the boron is in a planar environment), to construct hybrid organic-inorganic materials [26].
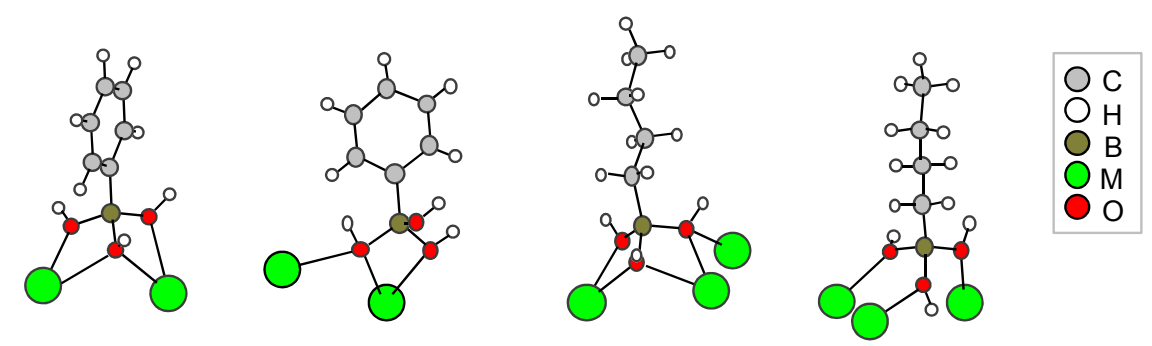

Figure 5. Coordination modes of phenyl and butylboronate ligands with respect to alkaline earth metals $(\mathrm{M}=\mathrm{Ca}, \mathrm{Sr})$ [22-24]. For the octylboronate ligand, the same binding mode as for the butylboronate was observed [24]. Adapted with permission from [22] (copyright American Chemical Society, 2011), [23,24] (copyright Wiley-VCH Verlag 2013 and 2015) and [25] (copyright Actualité Chimique, 2014).

\subsection{Benzoxaborolate-Based Crystal Structures with Alkaline-Earth Metals}

The synthetic strategy used in the case of benzoxaborolates is the same as for the boronates. The simplest benzoxaborolate (Figure $2 \mathrm{~b}$ ) was precipitated using an aqueous solution of alkaline earth metal, the reaction being carried out at room temperature, under reflux, or using hydrothermal conditions (Figure 6) [27]. In the vast majority of cases, microcrystalline precipitates were obtained, except for two phases, for which single crystals suitable for X-ray diffraction analyses were isolated.

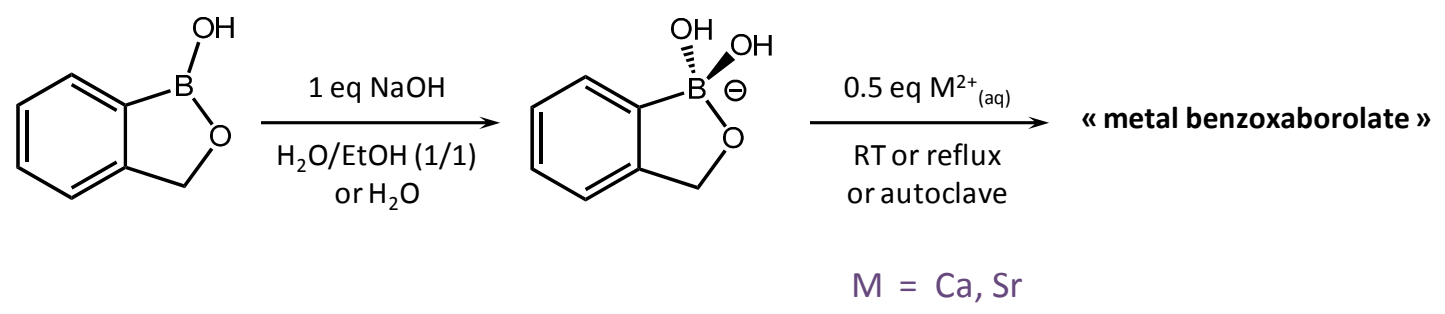

Figure 6. Reaction scheme for the formation of metal benzoxaborolate crystalline structures by precipitation.

To date, the structures of three phases have been solved: two involving $\mathrm{Mg}^{2+}$ and one $\mathrm{Ca}^{2+}$ [27]. Although these structures have an overall layered organization, as shown by powder X-ray diffraction analyses, the benzoxaborolates here play two different roles: either they bridge different metal cations, or they simply serve as counter-anions, as illustrated in Figure 7 for the Mg-benzoxaborolate decahydrate phase. 


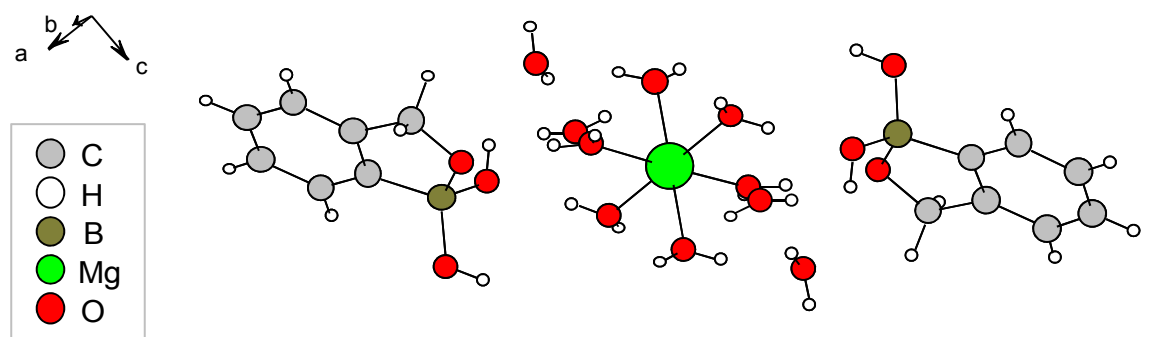

Figure 7. Coordination environment of $\mathrm{Mg}^{2+}$ in the $\mathrm{Mg}$-benzoxaborolate decahydrate phase, showing that the metal cation is linked to 6 water molecules, while the benzoxaborolate anions balance the charge [27].

Based on the crystal structures solved, several coordination modes to $\mathrm{Mg}^{2+}$ and $\mathrm{Ca}^{2+}$ have been identified for benzoxaborolates (Figure 8). Clearly, a very large diversity of binding modes is present, the benzoxaborolate anion being bound to 1 to 3 different metal cations, with both the $\mathrm{OH}$ groups and the oxygen atom of the cycle serving as binding sites. Interestingly, in the case of the Ca phase, a deprotonated anion was also observed (Figure 8, dashed orange line). Forming such a deprotonated species was somewhat unexpected given that reactions had been carried out in water, and that so far deprotonated benzoxaborolates had only been observed when working in anhydrous conditions [28]. It is interesting to notice that in this Ca-benzoxaborolate structure, in which both planar and tetrahedral benzoxaborolate anions are present [27], the $\mathrm{Ca} \ldots$ O distances are all essentially the same, meaning that the $\mathrm{Ca}$... O distance is not directly dependant on the protonation state of the oxygen in the benzoxaborolate.
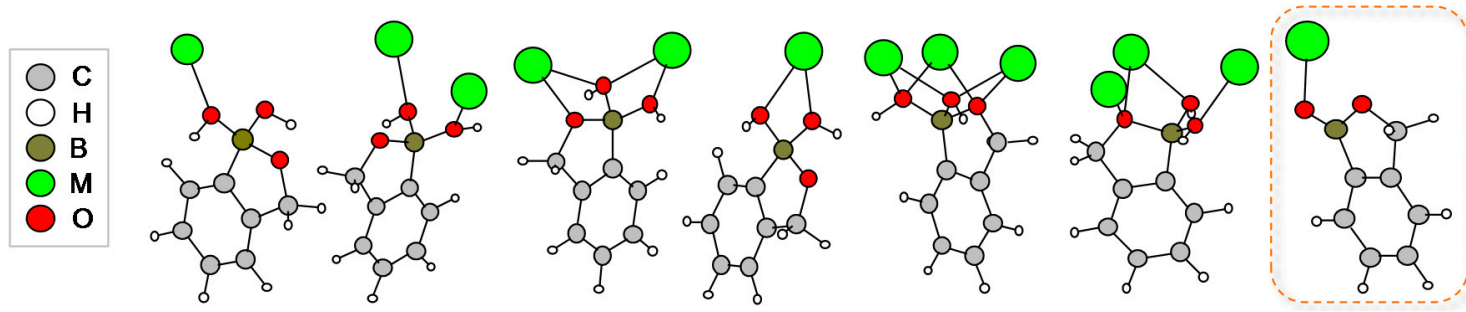

Figure 8. Coordination modes of the simplest benzoxaborolate ligand with respect to alkaline earth metals $(\mathrm{M}=\mathrm{Mg}, \mathrm{Ca})$. The deprotonated benzoxaborolate found in the Ca structure is outlined in dashed orange. Adapted with permission from [27] (copyright American Chemical Society, 2015).

\section{Boronate and Benzoxaborolate Spectroscopic Signatures in Materials}

\subsection{Solid State NMR}

Each of the materials presented in the previous section was characterized by multinuclear solid state NMR. Such characterization is useful not only to validate the structural models proposed on the basis of the X-ray diffraction analyses, but also to establish the NMR signatures of boronate and benzoxaborolate anions in solids, which can then be helpful for the study of more complex organic-inorganic materials.

Among the different NMR-active nuclei present in boronates and benzoxaborolates $\left({ }^{1} \mathrm{H},{ }^{13} \mathrm{C},{ }^{11} \mathrm{~B}\right.$, ${ }^{17} \mathrm{O}$ ), boron-11 is the most straightforward to look at by solid state NMR. It is a spin-3/2 quadrupolar nucleus of high natural abundance $(\sim 80 \%)$, which allows to clearly distinguish ${ }^{11} \mathrm{~B}$ atoms depending on whether they are in a planar or tetrahedral environment [29]. The ${ }^{11} \mathrm{~B}$ magic angle spinning (MAS) solid state NMR spectra of some of the alkaline-earth metal boronate and benzoxaborolate structures are shown in Figure 9. In both cases, very different spectra are obtained for the organoboron anions, in comparison to the corresponding boronic acid and benzoxaborole forms, both in terms of chemical shift 
$\left(\delta_{\text {iso }}\right)$, and of quadrupolar parameters $\left(\mathrm{C}_{\mathrm{Q}}\right.$ and $\left.\eta_{\mathrm{Q}}\right)$. For example, for boronic acids and benzoxaboroles, $\mathrm{C}_{\mathrm{Q}} \sim 2.8-3.3 \mathrm{MHz}$, while for boronates and benzoxaborolates, $\mathrm{C}_{\mathrm{Q}} \sim 1.1-1.5 \mathrm{MHz}$.

Concerning boronates, the ${ }^{11} \mathrm{~B}$ lineshape depends on the nature of the organic chain linked to the boron, and on the coordination environment of the anion. In cases when several coordination environments are present in a crystal structure, these can be resolved using 2-dimensional experiments like the multiple-quantum magic angle spinning (MQMAS [29,30]) experiment [23]. Concerning benzoxaborolates, different signatures are observed for the tetrahedral benzoxaborolate anions depending on their local environment in the crystal structure. Moreover, the deprotonated benzoxaborolate anion identified in the Ca-benzoxaborolate phase (in which the boron is in a planar configuration-see Figure 8 ) has a completely different ${ }^{11} \mathrm{~B} N \mathrm{NR}$ signature, with $\delta_{\text {iso }}$ and $\mathrm{C}_{\mathrm{Q}}$ values more similar to those of the benzoxaborole, but with a different asymmetry parameter $\eta_{\mathrm{Q}}$ [27].

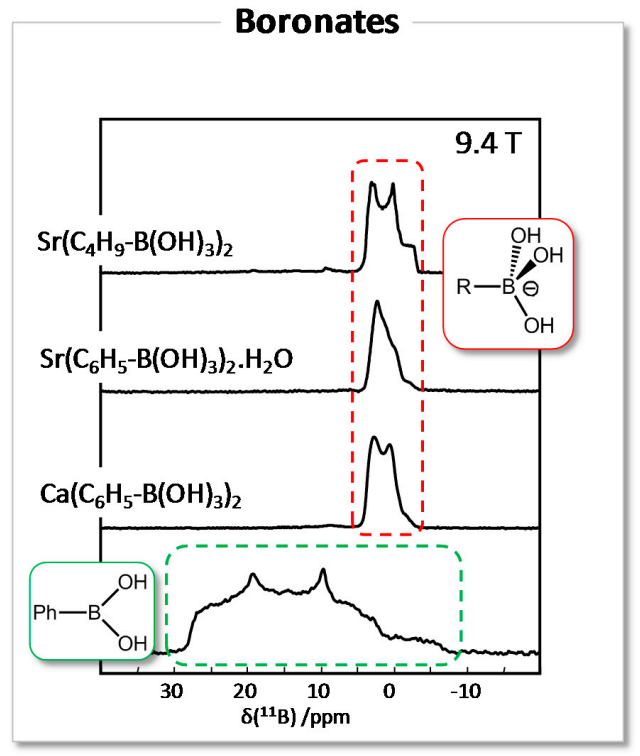

(a)

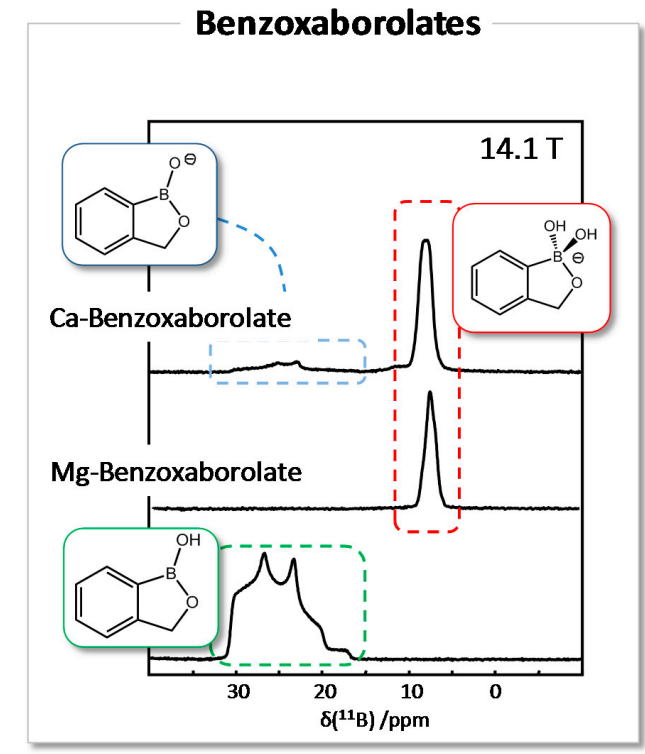

(b)

Figure 9. ${ }^{11} \mathrm{~B}$ solid state NMR spectra of alkaline-earth metal boronates (a) and benzoxaborolates (b), as well as for the corresponding boronic acid and benzoxaborole. The spectra shown here were recorded under MAS at two different magnetic fields (9.4 T for boronic acids, vs. $14.1 \mathrm{~T}$ for benzoxaboroles), and present second order quadrupolar lineshapes. Adapted with permission from [27] (copyright American Chemical Society, 2015).

${ }^{13} \mathrm{C}$ solid state NMR experiments have also been carried out on the different materials. In the case of the butylboronate phases, they were found to be particularly useful to validate the structural model proposed by X-ray diffraction [23]. ${ }^{1} \mathrm{H}$ solid state NMR analyses, performed using either fast MAS conditions and/or with ${ }^{1} \mathrm{H}$ homonuclear decoupling sequences (e.g., DUMBO- decoupling under mind-boggling optimization [31]), were shown to be informative on the number of strong $\mathrm{H}$-bonds present in the materials, and to complement well the studies performed using infra-red (IR) spectroscopy [22-24]. Finally, it should be noted that ${ }^{17} \mathrm{O}$ solid state NMR experiments have not been reported on these phases so far, due to its very unfavorable NMR properties (very low natural abundance and low resonance frequency) [29,32].

Another way to gain insight into the structure of coordination networks involving boronate and benzoxaborolate ligands consists of studying the NMR signatures of the metal ions to which they are bound. Most of the crystalline structures mentioned above have been characterized using ${ }^{25} \mathrm{Mg}$, ${ }^{43} \mathrm{Ca}$ and ${ }^{87} \mathrm{Sr}$ solid state NMR, as illustrated in Figure 10. Alkaline earth metals are very challenging for NMR, due to their low resonance frequency, low natural abundance, and/or large quadrupole 
moment, and their isotopic enrichment is costly [33-35]. Nevertheless, ${ }^{25} \mathrm{Mg},{ }^{43} \mathrm{Ca}$, and ${ }^{87} \mathrm{Sr} \mathrm{NMR}$ spectra can provide important clues concerning the local environments of the metals. In particular, $\delta_{\text {iso }}\left({ }^{43} \mathrm{Ca}\right)$ is highly informative about the local structure around calcium, and it was shown that it could be used as a very sensitive probe for positioning the boronate $\mathrm{O}-\mathrm{H}$ groups around the $\mathrm{Ca}^{2+}$, using a combined experimental-computational approach based on advanced DFT calculations [22].
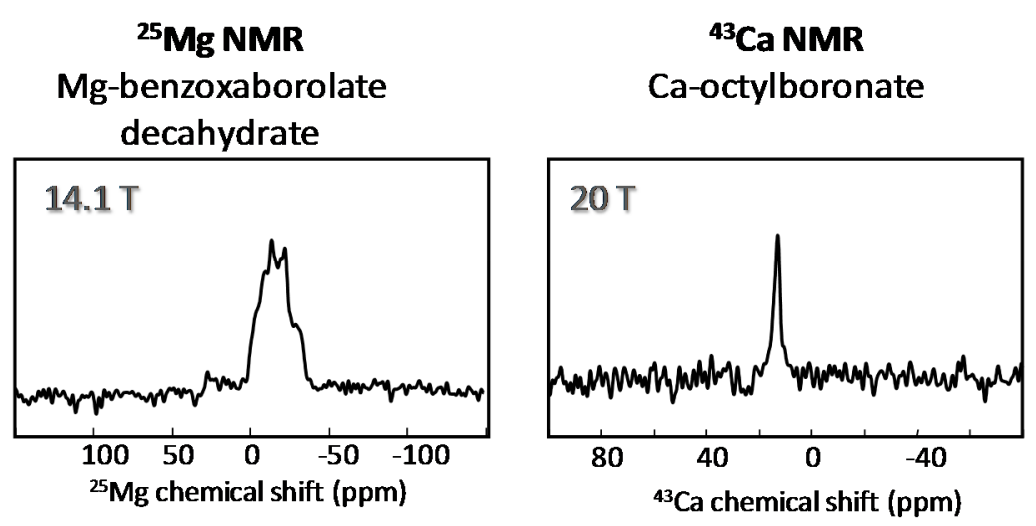
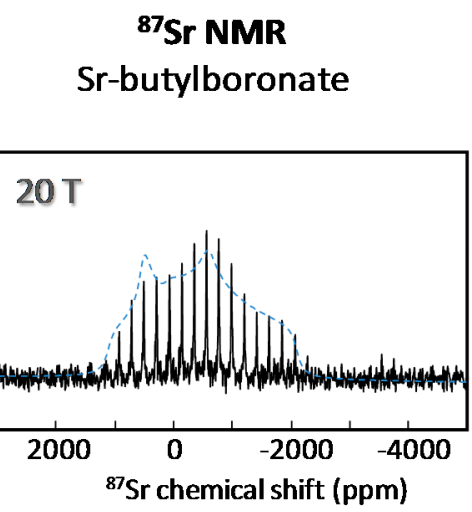

Figure 10. Natural abundance ${ }^{25} \mathrm{Mg},{ }^{43} \mathrm{Ca}$ and ${ }^{87} \mathrm{Sr}$ solid state NMR spectra of metal boronates/ benzoxaborolates, recorded at 14.1 or $20 \mathrm{~T}$. The experimental conditions for each spectrum can be found in the corresponding publications. Adapted with permission from [24] (copyright Wiley-VCH, 2015), and [27] (copyright American Chemical Society, 2015).

\subsection{Infrared Spectroscopy}

Within the crystal structures of alkaline-earth metal boronates and benzoxaborolates, other weak interactions are present in addition to the metal-ligand ones. In particular, hydrogen-bonds play a key role. They can be identified easily by infrared spectroscopy, leading to broad bands between $\sim 3500$ and $2900 \mathrm{~cm}^{-1}$. The other $\mathrm{OH}$ groups, which are not involved in any H-bonding, lead to sharper bands at higher frequencies, as illustrated in Figure 11 for two phenylboronate phases.

To go further in the interpretation of these IR spectra, the O-H stretching modes were calculated by DFT, starting from the crystal structures in which the protons had been positioned using an "NMR-crystallography" type of approach [22-24]. As shown in Figure 11, although small shifts remain between experimental and calculated values, DFT calculations can nevertheless be useful to identify some of the stretching bands, such as those belonging to the bridging water molecules in the case of the $\mathrm{Sr}\left(\mathrm{C}_{6} \mathrm{H}_{5}-\mathrm{B}(\mathrm{OH})_{3} \cdot \mathrm{H}_{2} \mathrm{O}\right.$ phase [24]: the O-H stretching modes of water appear as a broad resonance beneath the sharper $\mathrm{C}-\mathrm{H}$ stretching frequencies of the phenyl group.

Overall, the studies performed on the alkaline-earth metal boronates and benzoxaborolates have shown that the use of multinuclear solid state NMR and infra-red spectroscopy, in conjunction with DFT calculations, are essential to fully grasp the structure of the coordination networks. This is particularly true when trying to establish the H-bond network in structures for which no single-crystal X-ray diffraction data were available. Understanding in detail the structure of boronate-based coordination networks can be of importance to fully rationalize their properties, and hence combining advanced spectroscopic analyses with advanced computational methods is crucial. 


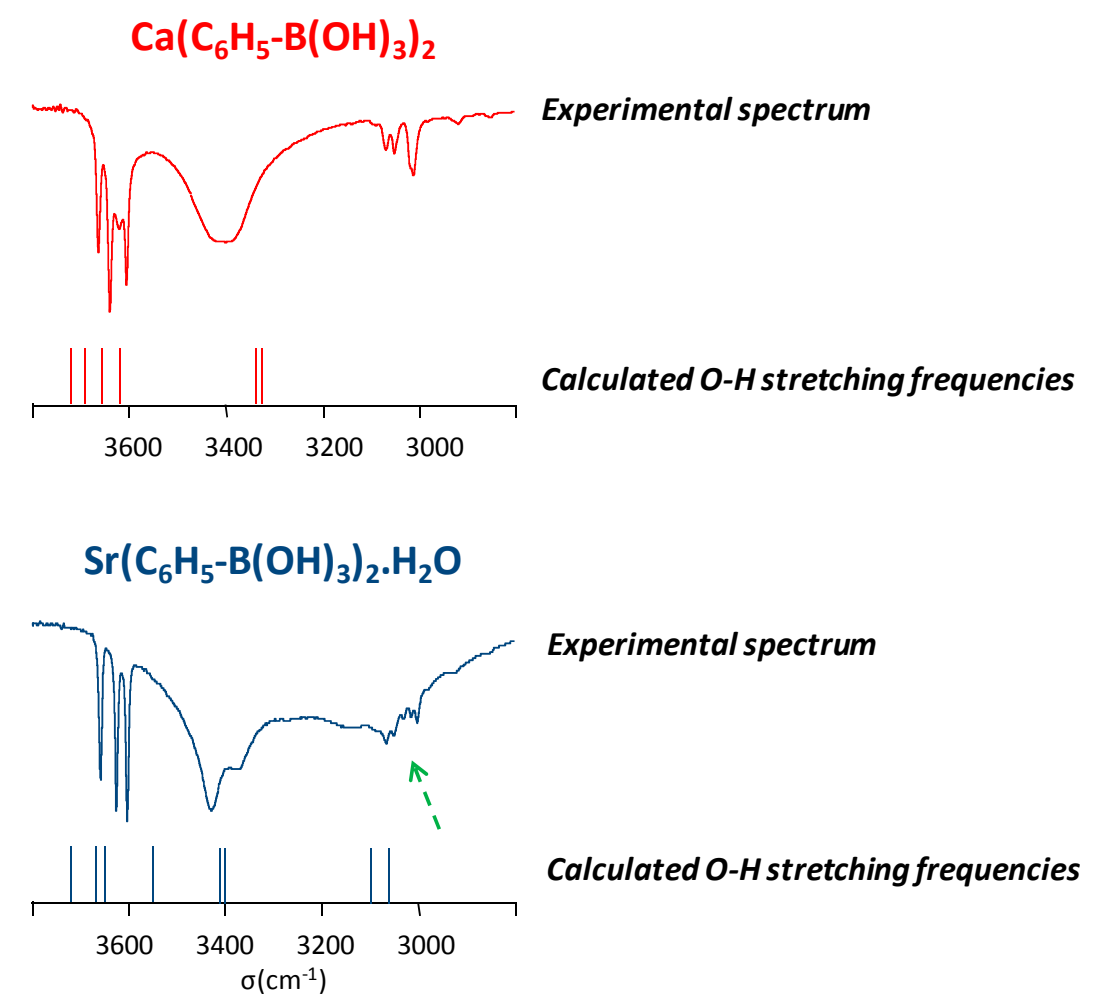

Figure 11. Portion of the experimental IR spectra of the Ca-phenylboronate and Sr-phenylboronate monohydrate phases, and representation of the DFT-calculated $\mathrm{O}-\mathrm{H}$ stretching frequencies for these structures. The dashed green arrow points to the $\mathrm{O}-\mathrm{H}$ bands identified as belonging to the water molecules (beneath the aromatic C-H stretching frequencies). Adapted with permission from [23] (copyright Wiley-VCH, 2013), and [24] (copyright Wiley-VCH, 2015).

\section{Emerging Applications of Materials Involving Boronates and Benzoxaborolates}

\subsection{New Functional Coordination Polymers Based on Boronates}

\subsubsection{Boronates as a New Class of Ligands}

In order to demonstrate the utility of boronate ligands for the construction of novel coordination networks, their coordination properties were compared to those of other tridentate ligands, such as phosphonates. Phosphonates are indeed already widely used for the preparation of MOFs and other hybrid materials [36]. Four Ca-phosphonate phases were thus synthesized, using either phenylphosphonate or butylphosphonate ligands: $\mathrm{Ca}\left(\mathrm{C}_{6} \mathrm{H}_{5}-\mathrm{PO}_{2}(\mathrm{OH})_{2}, \mathrm{Ca}\left(\mathrm{C}_{6} \mathrm{H}_{5}-\mathrm{PO}_{3}\right) \cdot 2 \mathrm{H}_{2} \mathrm{O}\right.$, $\mathrm{Ca}\left(\mathrm{C}_{4} \mathrm{H}_{9}-\mathrm{PO}_{2}(\mathrm{OH})\right)_{2}, \mathrm{Ca}\left(\mathrm{C}_{4} \mathrm{H}_{9}-\mathrm{PO}_{3}\right) \cdot \mathrm{H}_{2} \mathrm{O}$ [37]. The mode of binding of these phosphonates to $\mathrm{Ca}^{2+}$, whether in their simply deprotonated form $\mathrm{R}-\mathrm{PO}_{2}(\mathrm{OH})^{-}$or their fully deprotonated form R- $\mathrm{PO}_{3}{ }^{2-}$, were then compared to those of the phenylboronate $\left(\mathrm{C}_{6} \mathrm{H}_{5}-\mathrm{B}(\mathrm{OH})_{3}{ }^{-}\right)$and butylboronate $\left(\mathrm{C}_{4} \mathrm{H}_{9}-\mathrm{B}(\mathrm{OH})_{3}{ }^{-}\right)$anions. As shown in Figure 12, for each organic chain (phenyl or butyl), the modes of binding of the phosphonates differed from those of the boronates, whatever the protonation state of the phosphonate. Similar conclusions could also be drawn from the comparison of the strontium structures $\mathrm{Sr}\left(\mathrm{C}_{6} \mathrm{H}_{5}-\mathrm{B}(\mathrm{OH})_{3}\right)_{2} \cdot \mathrm{H}_{2} \mathrm{O}$ and $\mathrm{Sr}\left(\mathrm{C}_{6} \mathrm{H}_{5}-\mathrm{PO}_{2}(\mathrm{OH})\right)_{2}$ [22]. Overall, these comparisons underscore the difference and complementarity of boronates with respect to common ligands like phosphonates, and point to the fact that boronates can act as a new class of building blocks for preparing coordination polymers. 


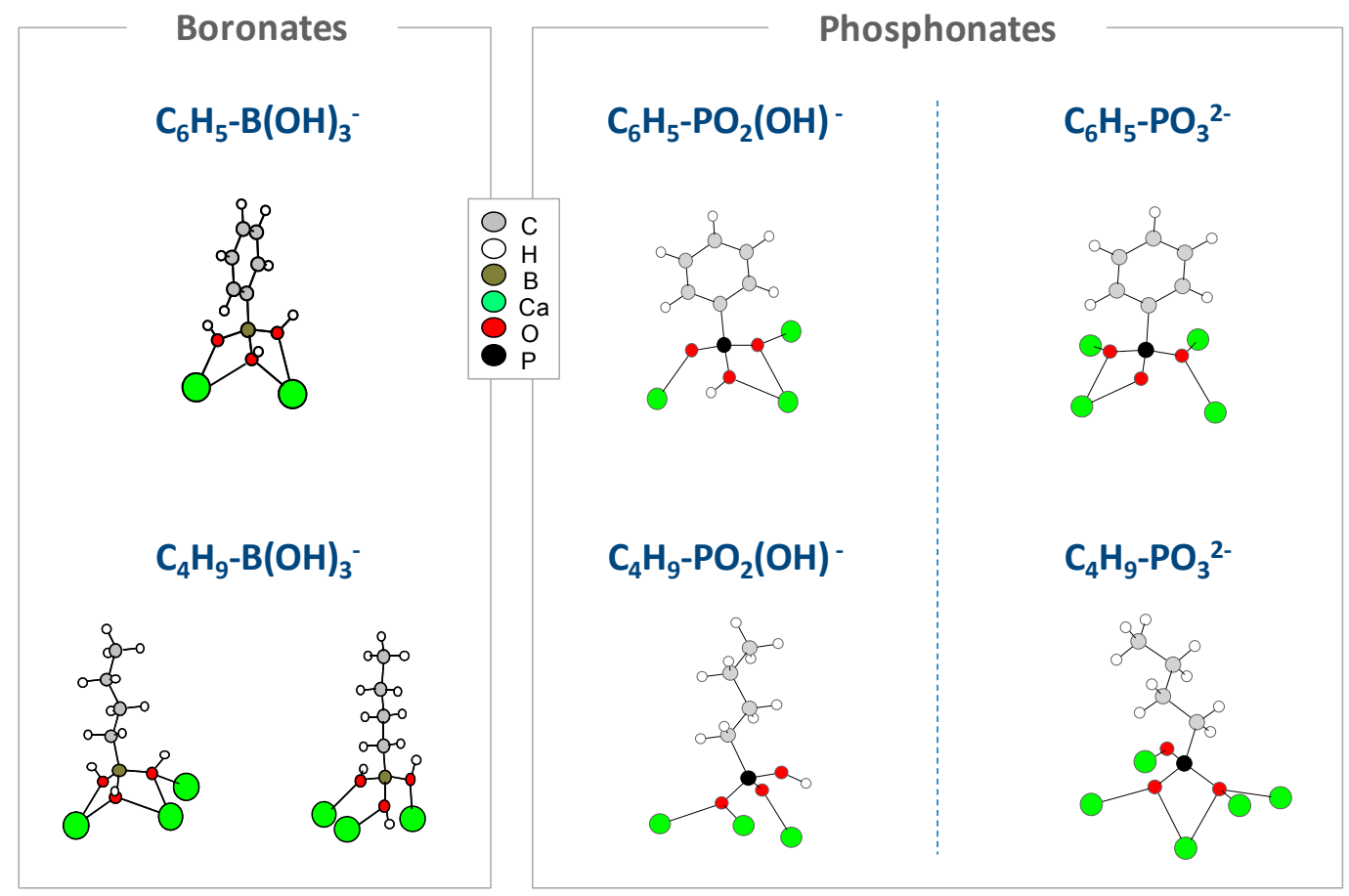

Figure 12. Comparison of the coordination modes observed for phosphonates and boronates with respect to calcium in different crystal structures. Adapted with permission from [22] (copyright American Chemical Society, 2011), [23,24] (copyright Wiley-VCH Verlag 2013 and 2015), [25] (copyright Actualité Chimique, 2014), and [37] (copyright Royal Society of Chemistry 2013).

\subsubsection{Structures Based on Mixed Boronate/Carboxylate Ligands}

Recently, Guillou and coworkers demonstrated the usefulness of boronate type ligands for preparing functional molecular materials [38]. A series of crystalline coordination polymers were synthesized using a mixed carboxylate-boronate ligand (prepared from 4-carboxyphenylboronic acid), and lanthanide ions $\left(\left(\mathrm{Pr}^{3+}-\mathrm{Nd}^{3+}, \mathrm{Sm}^{3+}-\mathrm{Lu}^{3+}\right.\right.$, and $\left.\mathrm{Y}^{3+}\right)$. They were characterized by various techniques including $X$-ray diffraction and multinuclear solid state NMR $\left({ }^{11} \mathrm{~B},{ }^{13} \mathrm{C}\right.$ and $\left.{ }^{89} \mathrm{Y} N M R\right)$. The luminescence and magnetic properties of the compounds were explored. Some of the materials were found to have temperature-dependent luminescent properties, which is interesting for the development of molecular thermometers. Moreover, the magnetic properties of the $\mathrm{Yb}^{3+}$ derivative were promising, as it was found to exhibit a single molecular magnet behavior. Overall, this shows that the way in which boronates coordinate to metal ions and thereby lead to new coordination networks in comparison to more conventional ligands like carboxylates and phosphonates is highly attractive to prepare novel functional materials.

\subsection{Hybrid Materials Involving Benzoxaborolates: Towards New Ways of Formulating Benzoxaborole Drugs}

With the increasing number of benzoxaborole-containing drugs under study, the possibility of formulating them in a wide range of common biomaterials needs to be explored. In particular, the fast expansion of nanomedicine has led to the development and use of a variety of nanoparticles for drug-delivery applications [39-41]. In this context, we have recently looked into the formulation of simple benzoxaboroles (including the antifungal drug AN2690) in two materials already studied in the pharmaceutical context: an inorganic nanomaterial (Mg-Al layered double hydroxide- $\mathrm{LDH}$ ) and a biopolymer (poly-L-lactic acid-PLLA) [27,42]. In the former case, the idea was to intercalate the benzoxaborole taken in its anionic form (benzoxaborolate) between the positively charged sheets of the LDH, while in the later case, the benzoxaborole was directly incorporated in the PLLA film. 
Concerning the LDH-based materials, several different characterization techniques were applied, in particular multinuclear solid state NMR $\left({ }^{11} \mathrm{~B},{ }^{13} \mathrm{C},{ }^{1} \mathrm{H},{ }^{27} \mathrm{Al},{ }^{25} \mathrm{Mg},{ }^{19} \mathrm{~F}\right)$ [27]. Interpretations of the ${ }^{11} \mathrm{~B}$ NMR spectra were made on the basis of the data which had been obtained for the crystalline alkaline-earth benzoxaborolate phases mentionned in section 2.3 and in Figure 9b. It was shown that the intercalation of the organoboron molecules was successful, and that both the benzoxaborole and benzoxaborolate forms could be present in the interlayer space. Moreover, it was found that the materials need to be stored at low temperature to avoid any degradation of the molecules in the interlayer space and to prevent any further evolutions of their layered organization towards second staging structures. Finally, release kinetics were studied in a simulated physiological fluid, showing a rapid release of the intercalated molecules due to exchange of the benzoxaborolates with the phosphates present in the medium [27]. Subsequently, it was possible to tune these release kinetics by preparing PLLA-LDH composite materials, which were obtained by dispersion of the intercalated LDH particles in a PLLA film [42]. Overall, these studies are the first to look into the structure of more complex hybrid organic-inorganic (nano)materials involving benzoxaborolates, and important conclusions regarding the choice of the biomaterial for benzoxaborole drug formulations could be reached. However, it should be noted that investigations are still in progress to understand better the mode of intercalation of benzoxaborolates with respect to inorganic materials like LDH, using combined experimental-computational approaches.

\section{Conclusions}

In this review, we have summarized some of the key results reported in recent years on crystalline structures involving boronate and benzoxaborolate anions, by emphasizing their coordination properties and spectroscopic signatures. Although the number of crystalline materials involving these anions is still scarce, the few examples reported to date underscore the true potential of these anions for the preparation of new coordination networks (with applications in magnetism or luminescence for example), or for the search of new means to formulate organoboron drugs. Among the future directions to explore, the elaboration of nanoversions of the boronate-based coordination networks will also need to be looked into, because this should help expand their range of properties, as already shown in the literature for other families of coordination networks [43,44].

Acknowledgments: This review mainly summarizes results which were obtained through studies supported by the ANR (ANR JCJC "BOROMAT"), the 7th European framework program (Marie Curie ERG 239206), and a CNRS PICS project (QMAT-NMR). Access to large scale facilities was an important part of this work: (1) $850 \mathrm{MHz}$ NMR spectrometer in Warwick (funded by the Birmingham Science City Advanced Materials projects with support from Advantage West Midlands (AWM) and part funded by the European Regional Development Fund (ERDF)); (2) synchrotron beamlines for powder X-ray diffraction (Soleil-project 20140477; PSI-SLS - project 20120147; (3) supercomputers for DFT calculations (GENCI-IDRIS Grant 097535, and CINES project x2015087394).

Author Contributions: All authors contributed to the experiments and discussions presented in this review.

Conflicts of Interest: The authors declare no conflict of interest. The funding sponsors had no role in the design of the study; in the collection, analyses, or interpretation of data; in the writing of the manuscript, and in the decision to publish the results.

\section{References}

1. Hall, D.G. Boronic Acids: Preparation and Applications in Organic Synthesis Medicine and Materials, 2nd ed.; Wiley-VCH: Weinheim, Germany, 2011.

2. Zheng, H.; Hall, D.G. Boronic acid catalysis: An atom-economical platform for direct activation and functionalization of carboxylic acids and alcohols. Aldrichim. Acta 2014, 47, 41-51.

3. Sun, X.; Zhai, W.; Fossey, J.S.; James, T.D. Boronic acids for fluorescence imaging of carbohydrates. Chem. Commun. 2016, 52, 3456-3469. [CrossRef] [PubMed]

4. Brooks, W.L.A.; Summerlin, B.S. Synthesis and applications of boronic acid-containing polymers: From materials to medicine. Chem. Rev. 2016, 116, 1375-1397. [CrossRef] [PubMed] 
5. Kubo, Y.; Nishiyabu, R.; James, T.D. Hierarchical supramolecules and organization using boronic acid building blocks. Chem. Comm. 2015, 51, 2005-2020. [CrossRef] [PubMed]

6. Smoum, R.; Rubinstein, A.; Dembitsky, V.M.; Srebnik, M. Boron containing compounds as protease inhibitors. Chem. Rev. 2012, 112, 4156-4220. [CrossRef] [PubMed]

7. Adamczyk-Woźniak, A.; Borys, K.M.; Sporzyński, A. Recent developments in the chemistry and biological applications of benzoxaboroles. Chem. Rev. 2015, 115, 5224-5247. [CrossRef] [PubMed]

8. Dowlut, M.; Hall, D.G. An improved class of sugar-binding boronic acids, soluble and capable of complexing glycosides in neutral water. J. Am. Chem. Soc. 2006, 128, 4226-4227. [CrossRef] [PubMed]

9. Anacor Pharmaceuticals. Available online: www.anacor.com (accessed on 28 April 2016).

10. Clair, S.; Abel, M.; Porte, L. Growth of boronic acid based two-dimensional covalent networks on a metal surface under ultrahigh vacuum. Chem. Commun. 2014, 50, 9627-9635. [CrossRef] [PubMed]

11. Li, D.; Chen, Y.; Liu, Z. Boronate affinity materials for separation and molecular recognition: Structure, properties and applications. Chem. Soc. Rev. 2015, 44, 8097-8123. [CrossRef] [PubMed]

12. Cambre, J.N.; Sumerlin, B.S. Biomedical applications of boronic acid polymers. Polymer 2011, 52, 4631-4643. [CrossRef]

13. Li, H.; Wang, H.; Liu, Y.; Liu, Z. A benzoboroxole-functionalized monolithic column for the selective enrichment and separation of cis-diol containing biomolecules. Chem. Commun. 2012, 48, 4115-4117. [CrossRef] [PubMed]

14. Zhao, Y.; Trewyn, B.G.; Slowing, I.I.; Lin, V.S.-Y. Mesoporous silica nanoparticle-based double drug delivery system for glucose-responsive controlled release of insulin and cyclic AMP. J. Am. Chem. Soc. 2009, 131, 8398-8400. [CrossRef] [PubMed]

15. Ding, S.-Y.; Wang, W. Covalent organic frameworks (COFs): From design to applications. Chem. Soc. Rev. 2013, 42, 548-568. [CrossRef] [PubMed]

16. Lorand, J.P.; Edwards, J.O. Polyol complexes and structure of the benzeneboronate ion. J. Org. Chem. 1959, 24, 769-774. [CrossRef]

17. Cammidge, A.N.; Goddard, V.H.M.; Gopee, H.; Harrison, N.L.; Hughes, D.L.; Schubert, C.J.; Sutton, B.M.; Watts, G.L.; Whitehead, A.J. Aryl trihydroxyborates: Easily isolated discrete species convenient for direct application in coupling reactions. Org. Lett. 2006, 8, 4071-4074. [CrossRef] [PubMed]

18. Babcock, L.; Pizer, R. Dynamics of boron acid complexation reactions. Formation of 1:1 boron acid-ligand complexes. Inorg Chem. 1980, 19, 56-61. [CrossRef]

19. Tomsho, J.W.; Pal, A.; Hall, D.G.; Benkovic, S.J. Ring structure and aromatic substituent effects on the $\mathrm{p} K_{\mathrm{a}}$ of the benzoxaborole pharmacophore. ACS Med. Chem Lett. 2012, 3, 48-52. [CrossRef] [PubMed]

20. Haynes, W.M. Handbook of Chemistry and Physics, 92nd ed.; CEC Press: Boca Raton, FL, USA, 2011-2012.

21. Popov, K.; Rönkkömäki, H.; Lajunen, L.H. Critical evaluation of the stability constants of phosphonic acids. Pure Appl. Chem. 2001, 73, 1641-1677. [CrossRef]

22. Reinholdt, M.; Croissant, J.; Di Carlo, L.; Granier, D.; Gaveau, P.; Bégu, S.; Devoisselle, J.-M.; Mutin, H.; Smith, M.E.; Bonhomme, C.; et al. Synthesis and characterization of crystalline structures based on phenylboronate ligands bound to alkaline earth cations. Inorg. Chem. 2011, 50, 7802-7810. [CrossRef] [PubMed]

23. Sene, S.; Reinholdt, M.; Renaudin, G.; Berthomieu, D.; Zicovich-Wilson, C.M.; Gervais, C.; Gaveau, P.; Bonhomme, C.; Filinchuk, Y.; Smith, M.E.; et al. Boronate ligands in materials: Determining their local environment by using a combination of IR/solid-state NMR spectroscopies and DFT calculations. Chem. Eur. J. 2013, 19, 880-891. [CrossRef] [PubMed]

24. Berthomieu, D.; Gervais, C.; Renaudin, G.; Reinholdt, M.; Sene, S.; Smith, M.E.; Bonhomme, C.; Laurencin, D. Coordination polymers based on alkylboronate ligands: Synthesis, characterization, and computational modeling. Eur. J. Inorg. Chem. 2015, 2015, 1182-1191. [CrossRef]

25. Laurencin, D. Les acides boroniques et les boronates, des briques élémentaires pour la construction de matériaux. Actual. Chim. 2014, 391, 23-31.

26. Wang, S.; Alekseev, E.V.; Miller, H.M.; Depmeier, W.; Albrecht-Schmitt, T.E. Boronic acid flux synthesis and crystal growth of uranium and neptunium boronates and borates: A low-temperature route to the first neptunium(V) borate. Inorg. Chem. 2010, 49, 9755-9757. [CrossRef] [PubMed] 
27. Sene, S.; Bégu, S.; Gervais, C.; Renaudin, G.; Mesbah, A.; Smith, M.E.; Mutin, P.H.; van der Lee, A.; Nedelec, J.-M.; Bonhomme, C.; et al. Intercalation of benzoxaborolate anions in layered double hydroxides: Toward hybrid formulations for benzoxaborole drugs. Chem. Mater. 2015, 27, 1242-1254. [CrossRef]

28. Jaśkowska, E.; Justyniak, I.; Cyrański, M.K.; Adamczyk-Woźniak, A.; Sporzyński, A.; Zygadło-Monikowska, E.; Ziemkowska, W. Benzoxaborolate ligands in group 13 metal complexes. J. Organomet. Chem. 2013, 732, 8-14. [CrossRef]

29. MacKenzie, K.J.D.; Smith, M.E. Multinuclear Solid State NMR of Inorganic Materials; Pergamon Elsevier: Oxford, UK, 2002.

30. Frydman, L.; Harwood, L.J.S. Isotropic spectra of half-integer quadrupolar spins from bidimensional magic-angle spinning NMR. J. Am. Chem. Soc. 1995, 117, 5367-5368. [CrossRef]

31. Sakellariou, D.; Lesage, A.; Hodgkinson, P.; Emsley, L. Homonuclear dipolar decoupling in solid-state NMR using continuous phase modulation. Chem. Phys. Lett. 2000, 319, 253-260. [CrossRef]

32. Ashbrook, S.E.; Smith, M.E. Solid state O-17 NMR-An introduction to the background principles and applications to inorganic materials. Chem. Soc. Rev. 2006, 35, 718-735. [CrossRef] [PubMed]

33. Freitas, J.C.C.; Smith, M.E. Recent Advances in solid-state Mg-25 NMR spectroscopy. Ann. Rep. NMR Spectrosc. 2012, 75, 25-114.

34. Laurencin, D.; Smith, M.E. Development of ${ }^{43}$ Ca solid state NMR spectroscopy as a probe of local structure in inorganic and molecular materials. Prog. Nucl. Magn. Reson. Spectrosc. 2013, 68, 1-40. [CrossRef] [PubMed]

35. Bonhomme, C.; Gervais, C.; Folliet, N.; Pourpoint, F.; Coelho Diogo, C.; Lao, J.; Jallot, E.; Lacroix, J.; Nedelec, J.-M.; Iuga, D.; et al. ${ }^{87} \mathrm{Sr}$ solid-state NMR as a structurally sensitive tool for the investigation of materials: Antiosteoporotic pharmaceuticals and bioactive glasses. J. Am. Chem. Soc. 2012, 134, 12611-12628. [CrossRef] [PubMed]

36. Guerrero, G.; Alauzun, J.G.; Granier, M.; Laurencin, D.; Mutin, P.H. Phosphonate coupling molecules for the control of surface/interface properties and the synthesis of nanomaterials. Dalton Trans. 2013, 42, 12569-12585. [CrossRef] [PubMed]

37. Sene, S.; Bouchevreau, B.; Martineau, C.; Gervais, C.; Bonhomme, C.; Gaveau, P.; Mauri, F.; Bégu, S.; Mutin, P.H.; Smith, M.E.; et al. Structural study of calcium phosphonates: A combined synchrotron powder diffraction, solid-state NMR and first-principle calculations approach. CrystEngComm 2013, 15, 8763-8775. [CrossRef]

38. Fan, X.; Freslon, S.; Daiguebonne, C.; Le Pollès, L.; Calvez, G.; Bernot, K.; Yi, X.; Huang, G.; Guillou, O.A. Family of lanthanide-based coordination polymers with boronic acid as ligand. Inorg. Chem. 2015, 54, 5534-5546. [CrossRef] [PubMed]

39. Couvreur, P. Nanoparticles in drug delivery: Past, present and future. Adv. Drug Deliv. Rev. 2013, 65, $21-23$. [CrossRef]

40. Argyo, C.; Weiss, V.; Bräuchle, C.; Bein, T. Multifunctional mesoporous silica nanoparticles as a universal platform for drug delivery. Chem. Mater. 2014, 26, 435-451. [CrossRef]

41. Zhang, K.; Xu, Z.P.; Lu, J.; Tang, Z.Y.; Zhao, H.J.; Good, D.A.; Wei, M.Q. Potential for layered double hydroxides-based, innovative drug delivery systems. Int. J. Mol. Sci. 2014, 15, 7409-7428. [CrossRef] [PubMed]

42. Sene, S.; McLane, J.; Schaub, N.; Bégu, S.; Mutin, P.H.; Ligon, L.; Gilbert, R.; Laurencin, D. Formulation of benzoxaborole drugs in PLLA: From materials preparation to in vitro release kinetics and cellular assays. J. Mater. Chem. B 2016, 4, 257-272. [CrossRef]

43. Spokoyny, A.M.; Kim, D.; Sumrein, A.; Mirkin, C.A. Infinite coordination polymer nano- and microparticle structures. Chem. Soc. Rev. 2009, 38, 1218-1227. [CrossRef] [PubMed]

44. Lin, W.; Rieter, W.J.; Taylor, K.M.L. Modular synthesis of functional nanoscale coordination polymers. Angew. Chem. Int. Ed. 2009, 48, 650-658. [CrossRef] [PubMed]

(C) 2016 by the authors; licensee MDPI, Basel, Switzerland. This article is an open access article distributed under the terms and conditions of the Creative Commons Attribution (CC-BY) license (http://creativecommons.org/licenses/by/4.0/). 